\title{
TEORIA E PRÁTICA NAS PESQUISAS COM FORMAC̣ÃO DE PROFESSORES: UMA COMPREENSÃO ABERTA À INTERAÇÃO COMUNICATIVA
}

\author{
Catia Piccolo Viero Devechi* \\ Gionara Tauchen** \\ Amarildo Luiz Trevisan***
}

RESUMO: O presente artigo visa discutir as possibilidades de uma aprendizagem comunicativa no tratamento das questões problemáticas da área de formação de professores. Para tanto, mapeamos as abordagens paradigmático-epistemológicas utilizadas para analisar a relação teoria e prática nas teses de doutorado sobre formação de professores defendidas nas universidades federais brasileiras no último triênio de avaliação CAPES $(2007,2008$, 2009). Buscamos, nas investigações que tratam sobre o assunto, apontar elementos comuns que possam permitir uma interação comunicativa no equacionamento dos mesmos problemas. É um esforço para reconhecer a pluralidade e a objetividade que têm alicerçado as produções educacionais sobre o assunto, buscando elencar elementos para encontrar horizontes de compreensão que auxiliem a melhor enfrentá-los.

Palavras-chave: Epistemologia; Pesquisa; Formação de Professores; Aprendizagem Comunicativa.

\footnotetext{
*Doutora em Educação pela Universidade Federal de Santa Catarina (UFSC) e Professora do Programa de Pós-Graduação em Educação da Universidade de Brasília (UnB). E-mail: devechi@unb.br

* *Doutora em Educação pela Pontifícia Universidade Católica do Rio Grande do Sul (PUC/RS); Professora Adjunta da Universidade Federal do Rio Grande (FURG) e Coordenadora do Programa de Pós-Graduação em Educação da FURG. E-mail: giotauchen@gmail.com

** * Doutor em Educação pela Universidade Federal do Rio Grande do Sul (UFRGS); Professor Associado da Universidade Federal de Santa Maria (UFSM) e Coordenador do Programa de Pós-Graduação em Educação UFSM. E-mail: trevisanamarildo@gmail.com
} 


\section{THEORY AND PRACTICE OF RESEARCH IN TEACHER EDUCATION: A VIEW OPENED TO COMMUNICATIVE INTERACTION}

ABSTRACT: The following article aims to discuss the possibilities of communicative learning in relation to questions concerning the area of teacher education. To this end, we mapped the paradigmatic-epistemological approaches used to analyze the theoretical and practical relation in $\mathrm{PhD}$ graduate studies on teacher education carried out in Brazilian public universities for the past three years of assessment by CAPES (2007 - 2009). In the investigations addressing this subject, we sought to point out the common elements that enable communicational interaction in the solving of the same problems. It is an effort to recognize the plurality and objectivity that have been basing the educational production on the subject, trying to gather elements that help in the understanding of how to better tackle them.

Keywords: Epistemology; Research; Teachers’ Education; Communicative Learning.

\section{CONSIDERACִ̃̃ES INICIAIS}

O artigo busca discutir a relação entre a teoria e a prática nas pesquisas com formação de professores no Brasil, utilizando-se da teoria discursiva de Habermas como parâmetro de análise diante da necessidade de desproblematizar os saberes da área e de reintegra-los ao contexto de ação. Pensamos em refletir a respeito da teoria do discurso como possibilidade metodológica de tratamento dos problemas da educação, pois essa proposta promete ir além das interpretações tácitas das práticas, das narrativas descritivas e subjetivas das experiências e dos imediatismos, tendo em vista o seu alicerce na comunicação racionalmente motivada. Percebendo tal teoria em suas manifestações de cunho epistemológico e não epistemológico, guiamos a discussão sob um olhar intersubjetivo da relação teoria e prática, refletindo sobre a possibilidade de uma maior adequação dos saberes produzidos diante da resistência mundana.

Para estruturação do estudo, procedemos a um mapeamento das teses de doutorado em educação que tratam da formação de professores, tendo como delimitação as que foram defendidas em universidades federais no último triênio de avaliação CAPES (2007, 2008 e 2009), disponibilizadas no portal Domínio Público. O recurso utilizado para o levantamento das fontes bibliográficas foi a busca por palavras-chave que tivessem relação com o tema, tais como: formação do professor, formação docente, formação de educadores ou formação do educador. Ao todo foram identificadas 49 teses 
provenientes das diferentes regiões do país, expressando uma possibilidade de compreensão do estado da arte das pesquisas realizadas na área.

Com o auxílio de tal fundamentação teórica, a partir da obra Verdade e justificação, de Habermas, elaboramos um esquema conceitual da teoria e da prática aberto à comunicação intersubjetiva como um recurso interpretativo para a análise das pesquisas educacionais com formações de professores no Brasil. Desse modo, tendo em vista os propósitos habermasianos de continuidade entre a ação e o discurso, avaliamos a possibilidade de pensar a prática e a teoria como elementos complementares, entendidos como espaços de problematização e desproblematização dos saberes. Para Habermas (2004), a prática tem a função de colocar em questão os saberes que não servem e à prova o que foi alcançado no discurso. Já o discurso tem o compromisso de desproblematizar o que foi apontado como problemático na prática. Trata-se de um movimento circular entre teoria e prática, entendidos por Habermas como ação e discurso, em que a aprendizagem depende da articulação entre ambos.

A proposta nos permite, por meio da racionalidade da comunicação, pensar num processo de continuidade entre o que a prática nos ensina na experiência com o mundo e o que aprendemos na troca argumentativa. Ou seja, não se trata de uma perspectiva solitária que busca conhecer, denunciar ou experienciar ações, mas de uma perspectiva que tem, na força argumentativa, a possibilidade racional de desproblematizar os saberes que serão reaplicados na ação. A prática é vista, desse modo, tanto como motivação para a renovação dos saberes inadequados quanto como espaço de prova das soluções discursivamente alcançadas.

Habermas permite um novo olhar sobre a relação teoria e prática: aposta num processo que não submete um lado a outro do problema, mas que vai ao encontro do propósito de renovar os discursos, possibilitando que ambos funcionem sempre de forma melhorada. A comunicação entre diferentes abordagens é fundamental para que se possa produzir saberes mais confiáveis e com mais chances de efetividade do que tem sido possível alcançar no limite das diversas perspectivas teórico-metodológicas. A partir do mapeamento das propostas, buscamos conhecer aquilo que, para Habermas, seriam os saberes prévios necessários ao saber renovado e à transcendência de toda justificação. Para o autor, "[...] o que importa ao mundo da vida é o papel de uma verdade bifronte, que serve de intermediária entre a certeza da ação e a assertibilidade discursivamente justificada [...]" (HABERMAS, 2004, 
p. 249). A aprendizagem depende da parceria entre as duas faces, sendo a ação medida pela adequação junto ao mundo e à teoria pela troca argumentativa.

A proposta assegura a necessidade da funcionalidade prática, sem abandonar o nível epistêmico atingido pelo discurso racionalmente motivado, permitindo a articulação da ação com o discurso como possibilidade de aprendizagem diante das necessidades das experiências cotidianas. É claro que as respectivas soluções dependerão sempre de serem buscadas por cada contexto ou cada realidade em particular e qualquer iniciativa maior deverá sempre ser construída conjuntamente. Por isto, estamos propondo, num primeiro momento, uma reflexão sobre o modelo da relação teoria e prática, a partir da perspectiva habermasiana, como hipótese, a fim de averiguar, num segundo momento, a sua valid'ade no confronto com outras perspectivas teóricas.

\section{AC̣ÃO E DISCURSO NA INTERAC̣ÃO COMUNICATIVA}

Habermas (2004) oferece a possibilidade de problematizar os saberes da prática e desproblematizá-los por meio do discurso. Alicerçando o fundamento epistemológico na argumentação racional de um grupo com competência comunicativa, e que segue pretensões de universalidade, ele identifica na integração com as práticas cotidianas a possibilidade da aprendizagem junto ao mundo. Uma vez identificadas as limitações e as resistências práticas, diante das soluções anteriormente oferecidas, é necessário revalidar os saberes por meio de argumentos racionais. Habermas diz, nesse sentido: “[...] tão logo as práticas ingênuas são interrompidas, as pretensões de validade só podem ser resgatadas discursivamente, ou seja, no interior do respectivo contexto de justificação [...]” (2004, p. 251).

Ao discurso cabe a tarefa de tratar as verdades falhas da ação. Aquilo que é desapontado enquanto insuficiência prática deve ser discutido, por meio da apresentação de razões, até o alcance de acordos. Vai para o discurso o que se mostrou insustentável diante das práticas mal sucedidas no mundo. Os discursos entram aqui como possibilidade de renovação das práticas abaladas, ou seja, como 
[...] máquinas de lavar: filtram aquilo que é racionalmente aceitável para todos. Separam as crenças questionáveis e desqualificadas daquelas que, por (um) certo tempo, recebem licença para voltar ao status de conhecimento não problemático [...] (HABERMAS, 2004, p. 63).

Forma-se assim um movimento circular entre o discurso e a ação. Quando a ação é desqualificada diante do mundo suposto como objetivo, as verdades até então tidas por verdadeiras (verdades não epistêmicas ${ }^{1}$ ) são encaminhadas ao discurso e transformadas em hipóteses justificadas até o alcance do consenso (HABERMAS, 2004). O esquema conceitual abaixo (Figura 1) ilustra a função do discurso de equacionar as verdades problemáticas para que elas possam ser devolvidas para a ação. A desproblematização das verdades significa permissão para retornar à atitude ingênua com o mundo, lugar em que as consequências práticas mostrar-se-ão bem-sucedidas ou não. Se a validade alcançada nos acordos não for adequada à ação, ela retorna ao discurso, sendo novamente discutida. Uma vez que a verdade é desproblematizada pelo discurso e reintegrada na ação, chegamos a bom termo com o mundo (HABERMAS, 2004).

Figura 1

Esquema conceitual da relação teoria e prática aberto à comunicação intersubjetiva. Fonte: Dados inferidos a partir da obra Verdade e justificação, de Habermas.

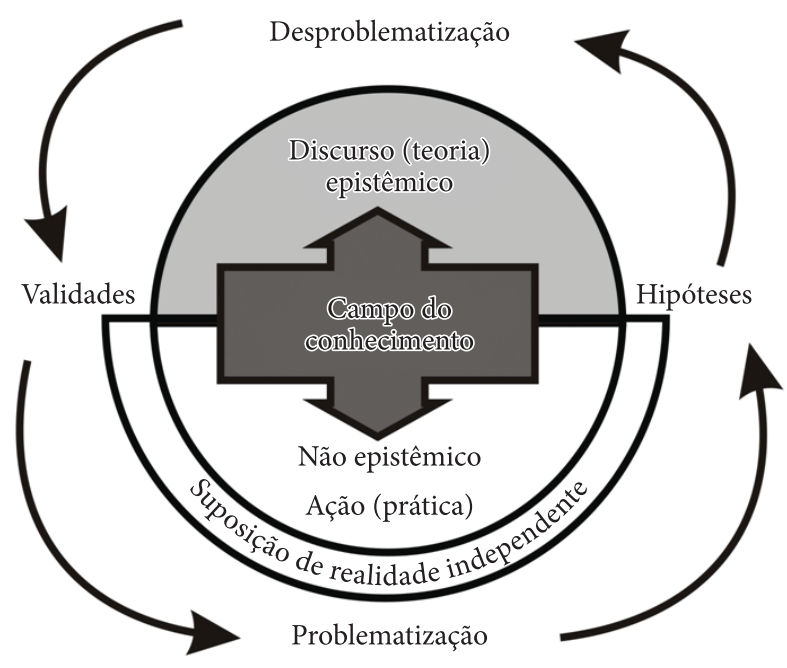


A figura nos permite perceber que estabelecemos no discurso uma relação pragmática com o mundo e debatemos pretensões de validade relativas ao contexto de ação. A desproblematização acontece no plano discursivo, entendido como espaço epistemológico, pelo qual é possível oferecer novas respostas à ação. No confronto com a prática, encontramos a possibilidade de crítica, aceitação ou não das expectativas discursivas, sendo as decepções processadas "com faculdade de juízo abdutivo", a partir da qual "revisamos o saber tornado problemático" (HABERMAS, 2004, p. 105). A ação é vista como contexto de informação problematizadora, mas também espaço de teste das soluções oferecidas pelo discurso. Enquanto o propósito desse último é alcançar validades que possam orientar a ação nos diferentes contextos, ela tem o compromisso de mostrar o sucesso do que foi acertado.

Habermas habilita assim a possibilidade de deliberar sobre os problemas da prática por meio da cooperação entre perspectivas racionais que possuem o compromisso de orientar as ações diante do mundo. Esse vínculo com o discurso garante um processo de aprendizagem que aposta na própria experiência possível perante o contexto. Segundo o autor, "[...] a posse reflexiva de juízos verdadeiros não seria possível se não pudéssemos corrigi-los e ampliá-los, isso é: também aprender algo mediante o relacionamento prático com uma realidade que nos resiste [...]" (HABERMAS, 2004, p. 105).Desse modo, são verdadeiras as proposições racionalmente justificadas e consensuadas que forem adequadas às práticas cotidianas ou, ainda, que atendam aos requisitos de uma prática bem-sucedida diante da resistência mundana. É por isso que

[...] um relacionamento racional com o saber só é possível graças à representação linguística do que se sabe e à confrontação do saber com uma realidade no contato com a qual uma expectativa fundamentada pode falhar. (HABERMAS, 2004, p. 105).

No discurso, agimos por hipóteses, pois não temos o compromisso direto com o mundo objetivo. Já na ação não podemos contar apenas com saberes falíveis; precisamos das informações completas e aparentemente sem riscos, caso contrário,

[...] não pisaríamos em nenhuma ponte, não utilizaríamos nenhum carro, não nos submeteríamos a nenhuma cirurgia, nem sequer levaríamos à boca uma refeição de preparo sofisticado se não considerássemos certos conhecimentos 
empregados, se não tivéssemos por verdadeiras as suposições consumidas na produção ou na execução (HABERMAS, 2004, p. 250-251).

Identificando as necessidades das certezas da ação, Habermas coloca o discurso a seu favor. Ou seja, não cabe apenas reconhecer os limites da ação, mas desproblematizá-los para serem reintegrados junto à realidade independente. Ainda segundo ele,

[...] os atores que chegam a um bom termo com o mundo nutrem-se de suas certezas da ação, mas, para os sujeitos que, na moldura dos discursos, se certificam reflexivamente de seu saber, a verdade e a falibilidade de um enunciado são dois lados da mesma moeda [...] (HABERMAS, 2004, p. 52).

Portanto, esta é uma instância pragmática que associa o discurso e a ação diante de um mundo suposto como objetivo que se coloca como oposição. Habermas se apoia na conexão entre ação e discurso na tentativa de alcançar um bom termo com o mundo real. A exigência de um transforma as certezas abaladas do outro em pretensões de validade problemáticas que só podem ser revalidadas por meio do convencimento mútuo.

Tal como, de um lado, o conceito de verdade permite traduzir as abaladas certezas de ação em enunciados problematizados, assim também manter a orientação pela verdade permite, de outro, retraduzir asserções discursivamente justificadas em certezas da ação restabelecidas [...] (HABERMAS, 2004, p. 259).

A exigência da ação certifica os acordos na experiência com o dado. Ou seja, a desproblematização das asserções passa por dois meios de prova: no discurso, as asserções são colocadas à prova à luz de razões; na ação, à luz de decepções na experiência com o mundo.

\section{DAS INTENÇÕES ÀS CONSIDERAC̣ÕES: O QUE EXPRESSAM OS ESTUDOS?}

Ao explicar o que é e para que serve uma tese, Umberto Eco a define como um trabalho "[...] no qual o estudante aborda um problema relacionado com o ramo de estudos em que pretende formar-se [...]" (2006, p. 1).Então, quais os problemas que movem os estudos de tese no campo da formação de professores? Quais as intencionalidades anunciadas 
por esses problemas? Que sugestões práticas emergem das conclusões dos problemas investigados? Como destaca o autor, é preciso "[...] demonstrar ser um estudioso capaz de fazer avançar a disciplina a que se dedica [...]" (ECO, 2006, p. 2). Em nosso caso, fazer avançar as compreensões para os problemas que envolvem a formação de professores. É nesse sentido que nos perguntamos: que espécie de relação com o conhecimento as pesquisas em educação no Brasil estão abordando? Que paradigmas epistemológicoeducacionais estão presentes no campo da formação de professores? É possível demonstrar o parâmetro articulador entre teoria e prática em cada uma das abordagens? Vejamos primeiramente como se configuram as abordagens teórico-paradigmáticas identificadas nos trabalhos de teses e, a seguir, o que elas sustentam sobre a relação teoria e prática.

As teses foram analisadas a partir da organização de um protocolo de informações sobre o tema, problema de pesquisa, objetivos, metodologia e principais referenciais teóricos. Nossas análises foram baseadas nos anúncios dos pesquisadores e, em alguns casos, nas compreensões que elaboramos acerca dos estudos, evidenciando que, das 49 teses investigadas, 17 são claramente fundamentadas no materialismo histórico, 18 estão fundamentadas na epistemologia da prática, 9 têm como alicerce fundamentador a perspectiva fenomenológica-hermenêutica, 6 encontram-se embasadas na epistemologia da complexidade, 5 são fundamentadas na teoria da representação social e 4 são pós-estruturalistas. Esta categorização não expressa, contudo, que as teses estejam ancoradas apenas nessas perspectivas ou que não comportem mais de uma perspectiva, ou seja, em algumas, os autores anunciam e afirmam suas posições; em outras, há uma tendência a essa perspectiva, evidenciada pelo processo metodológico, conceitos mobilizados e autores utilizados no diálogo.

Do conjunto de teses analisadas, cerca de 30\% expressam a intencionalidade de identificar elementos ou seus efeitos nos processos formativos. Citamos como exemplo: "Qual a inserção da pesquisa nos projetos de reestruturação curricular dos cursos de formação de professores, considerados os contextos de sua reformulação e implementação?" (BORTONILI, 2009, p. 23); "Quais as contribuições do percurso formativo propiciado no curso Normal Superior com Mídias interativas para o processo de reflexão dos professores?” (SANTOS, 2008, p. 18). Outros 30\% intencionam descrever processos e experiências: "Como pesquisadores/ mediadores/orientadores que participam de projetos típicos de comunidades de professores analisam a construção e consolidação de tais comunidades?” 
(ZANETTI, 2008, p. 90); Como professores de Literatura - aparentemente bem-sucedidos, segundo critérios estabelecidos -, enunciam sua prática pedagógica e como a relacionam aos princípios orientadores da reforma do ensino médio? (CABRAL, 2008, p. 82). Um conjunto significativo de teses, $40 \%$, não expressaram a questão norteadora ou problema de pesquisa por meio de questionamentos. Ou seja, não há um movimento de investigação suscitado pela pergunta, mas pela descrição da "problemática" de investigação.

Observamos que as sugestões de intervenção dos pesquisadores, neste movimento de desproblematização das práticas, expressam entendimentos compartilhados, pois apostam: na qualificação das práticas por meio de processos coletivos e compartilhados, seja em comunidades de aprendizagem, em redes ou outros espaços de comunicação; na compreensão e intervenção no plano político onde são forjados os interesses e ações de formação; no currículo como pauta central e (in)tensa da "configuração sócio-educativa" (MACEDO, 2010, p. 22); na formação como atividade que envolve condições e possibilidades de aprendizagem da pessoa integral e a pesquisa como estratégia de articulação teórico e prática.

Por isto, alguns trabalhos têm como ponto de convergência a investigação de processos que envolvem estudos curriculares de diversos cursos: Curso de Formação de Professores em Educação Física, da Universidade Estadual de Londrina (CESÁRIO, 2008); Curso de Formação de Educadores/as, promovido pelo Instituto Técnico de Capacitação e Pesquisa da Reforma Agrária - ITERRA, em convênio com a UERGS - Universidade Estadual do Rio Grande do Sul (WOLFF, 2007); Formação de Professores, na Universidade Federal de Uberlândia - UFU, na área de Ciências Exatas, nos cursos de Licenciatura em Física, Matemática e Química (MELO, 2007); Curso de Licenciatura Plena em Educação Infantil e Séries Iniciais do Ensino Fundamental (SILVA, 2008a); Programa Formação de Formadores a Distância (DAL-FORNO, 2009); Programa Institucional de Bolsas de Iniciação Científica do CNPq da Universidade do Estado da Bahia (PIRES, 2008); e pesquisas com docentes atuantes no Ensino Fundamental (PEREZ, 2008), com professores da Classe Hospitalar (BRANCO, 2008); aluno da Licenciatura em Matemática, no IFESP (MELO, 2008); e estudos com a formação de professores a partir das formulações das políticas públicas (TEIXEIRA, 2009; SILVA, 2009).

Esses pesquisadores, ao finalizarem a sistematização da tese, apontam, conforme destaca Minasi (2008, p. 193), “[...] algumas sugestões 
de saberes e recomendações que sejam capazes de contribuir na elaboração de novas propostas pedagógicas [...]",destacando-se: a inclusão da pesquisa como um dos pilares para a formação docente, a revisão dos currículos de formação de professores, a investigação sobre as trajetórias de vida, a resolução das contradições que fragmentam a formação, a coerência das práticas com os objetivos da formação (MINASI, 2008), a “[...] prática de ensino como o eixo articulador do curso [...]", a "formação do professor reflexivo" e a estruturação de "comunidades de aprendizagem" (CESÁRIO, 2008, p. 215). São sugeridas, de modo geral, a partir dos discursos dos pesquisadores, possibilidades de intervenção nas práticas futuras de formação de professores. Tratam-se de recomendações balizadas em experiências particulares, que ainda carecem encontrar, no discurso intersubjetivo, a possibilidade de realizar acordos sobre a viabilidade prática de tais sugestões.

Contudo, em um universo de 49 teses, encontramos anúncios de possibilidades de renovação das práticas em apenas 11 delas, ou seja, a grande maioria dos estudos é expressa com intencionalidade exploratória, descritiva e explicativa, informando, ao final, que tais considerações "[...] não pretendem concluir ou finalizar uma reflexão, mas sim oferecer uma sistematização dos dados encontrados nesta pesquisa a fim de permitir novas reflexões [...]" (PALOMINO, 2009, p. 180). Observa-se uma tendência aos particularismos, encerrando-se a produção teórica no próprio contexto da prática investigada, sem pretensão de universalidade. Contudo, se há convergência de muitos estudos no campo do currículo, por exemplo, não teríamos, no discurso intersubjetivo, o território para a solução de problemas comuns?

Em nossa investida, encontramos, ainda, um grupo de teses que situam as proposições no próprio marco teórico que as sustentou, ou seja, a teoria forneceu as lentes para a interpretação das práticas investigadas, possibilitando validar a própria teoria, como por exemplo:

[...] que as categorias freireanas de análise, de forma explícita ou implícita, tais quais: politicidade, criticidade, inacabamento relacional, problematização, dialogicidade e totalidade perpassam as falas, demonstrando assim que o Ideário Freireano oferece um referencial teórico-metodológico para a formação político-pedagógica do professor no ensino superior (ASSIS, 2007, p. 157).

Merece destaque, também, a subjetividade do pesquisador, evidenciada nas conclusões de algumas teses: 
Nesta etapa de encerramento da pesquisa situo-me como um intérprete das vivências, na condição de observador e observado, espaço onde indiquei e segui direções, onde criei e alterei conceitos, onde quebrei meus pré-conceitos e tentei facilitar para que os outros participantes também tornassem esses momentos de vivência significativos [...] (DIAS, 2007, p. 123).

As considerações da autora expressam que nossas teorias estão sempre em processo de reelaboração e reinterpretação e que somos sempre parte daquilo que buscamos entender. Ao compreender melhor o objeto, nos compreendemos, também, de forma diferente. Como destaca Lawn (2007, p. 63), “[...] nós não somos sujeitos ávidos por objetos, mas, sim, seres 'hermenêuticos' dentro da tradição”.

\section{OLHARES SOBRE A RELAC̣ÃO TEORIA E PRÁTICA}

A necessidade de articulação entre teoria e prática já é consenso nas discussões com a formação de professores, no entanto, o tipo de articulação estabelecido ainda é matéria de dúvida entre os pesquisadores da área. As abordagens teórico-paradigmáticas, em sua pluralidade epistemológica e ontológica, produzem compreensões bastante diferenciadas, tendo em vista que ora enfocam a teoria, ora a prática. Nesse sentido, buscamos analisar a relação teoria e prática de cada uma das abordagens identificadas, entendendo-as, numa linguagem habermasiana, como pretensões de validade a serem atestadas e contestadas pelo discurso.

Assegurando a necessidade do confronto entre as múltiplas perspectivas que tratam do mesmo assunto, procedemos a um enfrentamento, ainda que hipotético, das abordagens identificadas, com a esperança de que o movimento contrário possa ser feito. Ou seja, apresentaremos as nossas pretensões de validade que só poderão ser desempenhadas no confronto argumentativo com o outro. É o que defende Habermas (2004, p. 45), quando diz: "[...] a verdade de enunciados descritivos só pode ser fundamentada à luz de outros enunciados e a de opiniões empíricas, só com o auxílio de outras opiniões [...]". A validade dos saberes, para nós, não será alcançada por um discurso contextualista, mas por um discurso aberto às compreensões do coletivo alcançadas nas interações com o outro e com o mundo. Tal é o que buscamos atingir com as interpretações abaixo - uma comunicação 
aberta às críticas e refutações, ou seja, apenas um ponto de vista para uma comunicação mais ampliada e descentrada sobre o assunto.

Ao longo do nosso estudo, localizamos 17 teses fundamentadas no materialismo histórico, balizadas em autores como Marx, Engels, Gramsci, Althusser, Vygotsky, Saviani, Freire, Mészáros e Bourdieu. De modo geral, as teses expressam que a teoria é sempre histórica e nasce da prática. Logo, compreender uma prática significa conhecer seus elementos teóricos. Por isso, Minasi (2008, p. 60) destaca que o [...] conhecimento das leis da realidade objetiva ajuda a compreender mais adequadamente as causas dos acontecimentos em curso e constitui, por isso, base segura para atividade do ser humano dirigida no sentido de determinados fins. As condições históricas dos sujeitos e dos contextos influenciam o desenvolvimento das práticas educativas. Minasi (2008, p. 83) expressa que

[...] a teoria, como reflexo da prática, precisa ser entendida como um conjunto de conceitos sistematicamente organizado e que reflete a realidade dos fenômenos materiais sobre a qual foi construído e que serve para descrever, interpretar, explicar e compreender o mundo objetivo.

Teoria e prática são consideradas como uma unidade, sendo que a teoria nutre a prática social, representando a força transformadora. Assim, nessa perspectiva, as teses preocupam-se com a prática no sentido de denúncia, procurando explicar a formação das ideias ou discursos segundo a prática material, ligada à ideia de transformação dos meios de produção. A relação entre o teórico e o prático é determinada pelas relações materiais históricas. Trata-se de uma preocupação com a prática vista sob a lógica da transformação dos meios materiais de vida, anunciada nos problemas das teses que apontam questões históricas.

Na perspectiva do esquema de análise utilizado, as teses vinculadas ao materialismo histórico parecem desenvolver uma "teoria crítica da prática", visando uma práxis libertadora, tendo em vista que o pressuposto prático a ser alcançado já está a priori determinado: uma sociedade mais justa.

As 18 pesquisas fundamentadas na epistemologia da prática, sustentadas em autores como Tardif, Gauthier, Shulman e Pimenta, apoiam-se na compreensão que a caracteriza, segundo Tardif (2010, p. 255), como o "[...] estudo do conjunto dos saberes utilizados realmente pelos profissionais em seu espaço de trabalho cotidiano para desempenhar todas as suas tarefas 
[...]". Discutindo a formação de professores, Tardif (2010) concebe a prática como uma dimensão formativa dos saberes docentes, propondo a compreensão da natureza desses saberes e do papel que desempenham na profissão. Em se tratando de metodologia da pesquisa, isso significa sair dos meandros das universidades e realizar a investigação nos lugares onde as práticas de ensino ou o trabalho dos professores acontecem, ou seja, no trabalho intraescolar. Para o autor, os saberes docentes englobam

[...] os conhecimentos, as competências, as habilidades (ou aptidões) e as atitudes, isso é, aquilo que muitas vezes foi chamado de saber, saber-fazer, e saber-ser [...]. Esse enfoque considera que o profissional, sua prática e seus saberes não são entidades separadas, mas "copertencem" a uma situação de trabalho na qual "coevoluem” e se transformam [...] (TARDIF, 2010, p. 255-257).

A proposta de tal abordagem é revelar os saberes na prática dos profissionais em situações concretas de ação. Amaral (2008, p. 22) diz, em sua tese, que

[...] é fundamental construir canais de comunicação entre docentes e discentes na busca de alternativas e novas práticas que permitam uma formação para a docência que contemple entender o magistério como profissão, com saberes próprios, impregnados de questionamentos, estereótipos, anseios, prazer, satisfação.

Sendo assim, essa é uma abordagem “[...] que permite a apreensão, interpretação e descrição dos processos de decisão tomados pelos formadores diante de dilemas e dificuldades que encontram em seu contexto de atuação e dos conhecimentos implicados neles [...]” (DAL-FORNO, 2009, p. 82). Para Tardif (2010, p. 256),

[...] a finalidade de uma epistemologia da prática profissional é revelar esses saberes, compreender como são integrados concretamente nas tarefas dos profissionais e como eles os incorporam, produzem, utilizam, aplicam e transformam em função dos limites e dos recursos inerentes às suas atividades de trabalho.

Os saberes docentes são produzidos e legitimados na experiência da ação cotidiana dos professores. Sendo produtores de conhecimentos próprios, é necessário conhecer o que sabem e o que fazem nas suas atividades de ensino. Analisando tal abordagem, a partir do esquema conceitual aberto à interação comunicativa, pode-se dizer que as teses dedicam-se ao estudo 
no nível da ação e dos saberes não epistemológicos ${ }^{2}$, tendo em vista o enfoque nas práticas como elas acontecem. Partindo dessa compreensão, entendemos que as teses fundamentadas na epistemologia da prática parecem estar desenvolvendo "teoria da ação".

As 9 teses organizadas na perspectiva fenomenológica-hemenêutica interessam-se em saber como o conhecimento se constrói nas diferentes interações sociais, ancorando seus entendimentos em Gadamer, Husserl, Merleau-Ponty, Wilber, entre outros, na medida em que apostam na prática como espaço de significação a ser interpretado. Fundamentado na perspectiva fenomenológica-existencial de Husserl, Marinilson Silva (2008b) explica que o que denominamos mundo expressa o conjunto das nossas significações. Por isso, a fenomenologia será, para o autor, “[...] a ciência do que aparece à consciência, a ciência do sentido das coisas e do mundo [...]” (SILVA, 2008b, p. 49).Assim, preocupando-se com as significações existenciais, o conhecimento tem início com a intencionalidade do pesquisador na solução de um problema presente em seu cotidiano. Trata-se de compreender uma forma de existir/ser/estar no mundo em que a dimensão fundamental da consciência humana é histórica, sociocultural e se expressa através da linguagem (ESTEBAN, 2010, p. 63).

Essas abordagens interpretam os fatos tal como se percebem nos contextos, sendo a experiência subjetiva a base do conhecimento. Assim como a perspectiva habermasiana, tais abordagens também se alicerçam na experiência interpretativa, no entanto não apreendem as condições crítica da validação intersubjetiva. Preocupam-se com a atualização do sentido pelo intérprete, limitando a compreensão ao diálogo do intérprete com a prática, o que, para Habermas, deveria ser legitimado no discurso. Desse modo, as teses utilizam a teoria na interpretação e compreensão da prática. Interpretando tal abordagem pelo esquema de análise, tais teses parecem desenvolver "teoria sobre a prática".

As 6 teses que se fundamentam na epistemologia da complexidade ancoram suas construções especialmente no pensamento de Prigogine e Morin (2008, p. 335), o qual expressa que "[...] uma teoria não é o conhecimento; ela permite o conhecimento. Uma teoria não é uma chegada; é a possibilidade de uma partida. Uma teoria não é uma solução; é a possibilidade de tratar um problema [...]”. A teoria realiza-se na atividade pensante do sujeito, na sua capacidade de intervenção e criação, denominada por Morin de método. 
Na perspectiva da complexidade, “[...] a teoria é engrama, e o método, para ser estabelecido, precisa de estratégia, iniciativa, invenção, arte. Estabelece-se uma relação recorrente entre método e teoria [...]" (MORIN, 2008, p. 335). O método é atividade fenomenal, subjetiva e concreta. A teoria é um "meio-fim inscrito em permanente recorrência". Por isso, teoria e método são indispensáveis ao pensamento complexo. $\mathrm{O}$ método, atividade pensante e consciente do sujeito, é a atividade reorganizadora da teoria, expressando-se como a estratégia da complexidade.

Quando nos referimos ao sujeito, não o consideramos como individualidade isolada. Pelo contrário, o sujeito estrutura-se e se auto-organiza pela mediação dos outros sujeitos. Essa consideração é fundamental no plano do conhecimento, pois “[...] o desenvolvimento de um conhecimento objetivo no mundo deve avançar junto com um conhecimento subjetivo do outro [...]" (MORIN, 2007, p. 80). Assim, expressa que a compreensão só pode ocorrer de forma intersubjetiva. Na tese de Jussara Silva (2008a, p. 167) evidencia-se, na estruturação das compreensões do estudo, o “[...] reconhecimento da inseparabilidade da formação profissional e da produção da subjetividade; por instâncias de considerar a condição humana intrincada na processualidade da vida [...]".

Para a epistemologia da complexidade, prática e teoria são constituídas mutuamente por meio das interações e retroações que ocorrem na organização dos múltiplos sistemas que integramos e que nos integram. A teoria expressa a atividade pensante do sujeito que representa, reconstrói e traduz a sua atividade fenomenal subjetiva e objetiva, ou seja, a prática. Essa, por sua vez, envolvendo as auto-organizações do sujeito nas relações intersubjetivas com o outro, reorganiza a teoria, integrando um circuito em permanente recursividade capaz de produzir as emergências. Nessa perspectiva, as percepções expressam as teorias, nosso modo de ler e agir no mundo. Modificar as teorias e as práticas significa modificar o pensamento, ou seja, suas operações de organização. Interpretando essa abordagem pelo esquema de análise, tais teses desenvolvem uma "teoria complexa da prática".

As 5 pesquisas fundamentadas na teoria da representação social seguem especialmente a compreensão da psicologia social de Serge Moscovici, que aceita tanto o realismo ontológico como o epistemológico, ou seja, um realismo que pode ser tanto estudado quanto conhecido em alguns dos seus aspectos (CASTANÕN, 2004). Tais pesquisas buscam compreender 
os processos representacionais constituídos pelas “[...] mediações entre os sujeitos e o mundo, modos de ver objetos determinados, que implicam o processo simbólico que reconstrói o mundo e permite interagir com ele [...]". (BORTOLINI, 2009, p. 31). Propõem compreender as representações sociais que justificam as causalidades das práticas docentes por meio das observações e descrições de dados, e de uma "[...] teoria baseada em observações adequadas que seja o mais acurada possível [...]” (MOSCOVICI, 2011, p. 108). São modos de compreender as representações simbólicas da docência que "[...] possuem tantos elementos perceptuais quanto os assim chamados cognitivos [...]” (MOSCOVICI, 2011, p. 105). Segundo Oliveira (2008, p. 60),

A abordagem de Moscovici ultrapassa o esquema da díade S-O (sujeito-objeto) para a tríade, em que outros sujeitos também inter-atuam e incidem na relação $\mathrm{S}-\mathrm{O}[. .$.$] compreende-se o conhecimento como fenômeno ou fenômenos$ complexos que se geram em circunstâncias e dinâmicas de diversa índole, cuja construção está multideterminada por relações sociais e culturais.

As pesquisas fundamentadas nessa abordagem buscam compreender fenômenos complexos em torno da prática docente nos diferentes contextos, buscando algum tipo de mudança positiva nas representações. Segundo Perez (2008, p. 20), conhecer "[...] as representações sociais dos professores pode auxiliar a entender a elaboração e a veiculação dos conhecimentos [...]" também pode auxiliar a pensar como os sujeitos (professores e alunos) percebem e constroem os conceitos.

As teses fundamentadas na teoria da representação social apontam a prática constituída como representação dos seus sujeitos sociais, devendo ser conhecidas para que elas sejam mais bem planejadas e os sujeitos, melhor compreendidos, conduzidos ou orientados. Buscam conhecer as representações sociais constituídas na relação dos sujeitos com o mundo, possuindo, no entanto, um viés ontológico que pode ser conhecido em alguns dos seus aspectos (CASTANÕN, 2004). Analisado a partir do esquema conceitual de articulação comunicativa entre teoria e prática, o epistemológico está na compreensão do sujeito diante das representações do mundo. Tais teses, como elas se identificam, desenvolvem "teoria da representação social".

As 4 teses identificadas como pós-estruturalistas, inspiradas nas ideias de Derrida, Deleuze e Foucault, incluindo representantes dos estudos culturais como Stuart Hall, Silva, Costa e Harvey, defendem que a teoria 
e a prática se implicam uma na outra, pois "[...] a suposta separação entre teoria e prática, entre quem pensa e quem faz, entre o discurso e a prática, possibilita a profissão idealizada [...]" (BITTENCOURT, 2008, p. 42). Seguindo os propósitos de Foucault, Lázara Silva (2009, p. 38) diz que a base teórica seguida para "[...] respaldar o trabalho não atua com uma perspectiva de teoria desvinculada da prática, mas com um entendimento de que teoria e prática se implicam uma na outra". O objeto é produzido por meio dos discursos que o anunciam e esses "conformam" as possibilidades de percebê-lo e expressá-lo. Nessa perspectiva, a cultura constitui-se como território de lutas, de contestação e de disputas na construção dos sentidos, ou seja, toda ação e prática social é cultural e, por isso, expressa um significado, uma prática de significação. Para a autora,

[...] cada sujeito, a partir de seus traços singulares, irá se relacionar com o mundo à sua maneira. É esse sujeito que atribuirá um sentido ao enunciado, determinando o seu significado, que não acontece de forma neutra, mas sendo resultante do processo de agenciamento coletivo [...] (SILVA, 2009, p. 55).

As pós-estruturalistas apostam na prática como espaço interdisciplinar sustentado por diferentes tipos de discursos históricos que acontecem por meio de relações de poder e produzem saberes. A prática é vista como discurso a ser analisado, sendo esse sempre contextual. Ou seja, a prática é vista como espaço de multiplicidade que precisa ser analisado para que novas formas de compreensão social e individual sejam possíveis. Segundo Fischer (2001, p. 1),

[...] tudo é prática em Foucault. E tudo está imerso em relações de poder e saber, que se implicam mutuamente, ou seja, enunciados e visibilidades, textos e instituições, falar e ver constituem práticas sociais por definição permanentemente presas, amarradas às relações de poder, que as supõem e as atualizam.

Desse modo, a teoria seria parte das práticas discursivas. Para compreender é necessário entender a teoria e a prática de forma diluída. Segundo Fischer (2001, p. 2): "Analisar o discurso seria dar conta exatamente disso: de relações históricas, de práticas muito concretas, que estão “"vivas' nos discursos". Analisando tal abordagem pelo esquema conceitual que oferece um movimento circular entre prática e teoria, ou seja, passa pela prática, depois pela teoria e depois retorna à prática, pode-se dizer que essas 
teses voltam-se para a análise das práticas contextuais constituídas pelos discursos. Em síntese, podemos dizer que tais teses desenvolvem "teoria dos sentidos discursos”, pois também estão centradas na prática.

\section{DA PROBLEMATIZAC̣ÃO À DESPROBLEMATIZAC̣ÃO DISCURSIVA}

Os resultados da pesquisa explicitam o tipo de relação instituída entre teoria e prática nas teses que discutem a formação de professores no Brasil tendo, como recurso de análise, o esquema conceitual elaborado a partir da teoria do discurso de Habermas. As pesquisas com formação de professores têm apontado a importância insofismável da teoria para pensar a prática, dado que, sem esse aporte, os estudos sobre a formação ficariam presos no "praticismo", ou no mero acaso. Sublinham também a importância de refletir experiências concretas de processos formativos, pois sem o confronto da teoria com a prática toda a construção seria colocada em suspeita. Em síntese, há uma clara convicção de que o cultivo da teoria só faz sentido se estiver alicerçado na prática. Verificamos ainda que a indissociabilidade entre teoria e prática está presente nas pesquisas da área, independente das abordagens paradigmático-epistemológicas utilizadas.

A prática é compreendida no esquema sujeito-objeto, colocando-se, na maioria dos casos, como contexto a ser conhecido, valorizado, explicado ou denunciado. Há uma tendência a legitimar os saberes na dependência da indissociabilidade do sujeito interpretativo com as práticas vividas. No entanto, a articulação entre teoria e prática, mesmo ocorrendo de forma diferenciada em cada uma das abordagens, tem em vista a centralização em um desses elementos.

Analisando as teses a partir do esquema conceitual de articulação entre a teoria e a prática conforme os pressupostos habermasianos, percebemos que, apesar de todas sustentarem essa articulação, a prática parece ser utilizada apenas como elemento derivado da teoria em maior ou menor proporção. A relação com a prática segue o objetivo de oferecer alguma informação importante para a teoria. Nesse sentido, buscam identificar "quais" práticas têm sido desenvolvidas, ou descrever "como" elas têm acontecido, "valorizar" os saberes da forma como eles aconteceram, ou saber "o que pode" ser denunciado. Ou seja, não há uma continuidade 
entre a teoria e a prática, no sentido de um duplo papel, mas a elaboração de teorias centradas ora numa, ora na outra, o que se caracteriza, portanto, como "teoria sobre a prática", "teoria da prática", "teoria crítica da prática", "teoria dos sentidos discursos", "teoria complexa da prática" ou "teoria da representação social”. Na perspectiva do esquema conceitual, seriam tentativas de articulação que, por não tratarem a teoria como possibilidade de equacionamento dos problemas práticos, ficariam centradas mais no campo de aplicação da teoria à prática. Além disso, estariam mais próximas da definição teorias perspectivistas ou contextualistas, pois não possuem o discurso como recurso de validação.

Pode-se dizer que há uma tendência em centralizar a produção do conhecimento na prática ou na teoria, não permitindo a interação entre esses elementos, constituindo-se, em última instância, em teoria, pois não oferecem esquemas balizadores de equacionamento dos problemas práticos. Não há um processo de seguimento entre as contribuições da prática e as contribuições da teoria, o que pode distanciar a possibilidade de tratamento dos mesmos problemas. Mas, sim, apresentam uma forma de submissão de uma pela outra que diminui as chances de validação discursiva e a possibilidade de reparação dos equívocos de uma instância pela outra.

A partir do estudo da pragmática de Habermas é possível identificar a possibilidade de complementaridade de tal relação, considerando o propósito de a aprendizagem circular entre ação e discurso. A aprendizagem passa a ser vista como prosseguimento entre ambos, oferecendo a possibilidade racional de desproblematizar as práticas cotidianas e ultrapassando, nesse sentido, qualquer possibilidade individualista, contextualista, relativista ou tecnicista. Essa abordagem pode ampliar os impactos práticos das pesquisas com formação de professores sem abandonar o âmbito epistemológico necessário a uma validação mais universalizada dos saberes. O prolongamento entre a ação e o discurso permite desproblematizar os saberes pelo descentramento das individualidades e, ao mesmo tempo, certificar o sucesso na ação junto ao mundo.

\section{CONSIDERACְÕES FINAIS}

O artigo discute o compromisso das pesquisas com a formação de professores no Brasil com as consequências práticas de seus resultados, apontando a teoria discursiva de Habermas como recurso de análise das 
relações teoria e prática que têm sido estabelecidas. O estudo, de natureza pragmática e reconstrutiva, centrou-se na análise de 49 teses de doutorado que tratam da formação de professores, defendidas nas universidades federais brasileiras no último triênio de avaliação da CAPES (2007-2009). Os dados das pesquisas apresentam-nos as compreensões que têm sustentado a produção do conhecimento na área, explicitando elementos que nos permitem analisar o tipo de relação entre teoria e prática estabelecida. São relações que se diferenciam tanto na questão epistemológica como na ontológica, explicitando a preocupação da área em torno da efetivação dos saberes produzidos.

A partir da compreensão pragmática habermasiana, o objetivo foi repensar a teoria e a prática por um viés intersubjetivo, entendendo-as como elementos que se complementam no processo de aprendizagem entre a problematização e a desproblematização dos saberes da ação. Tornou-se possível, desse modo, inferir que existem nas teses a possibilidade de a teoria e a prática serem vistas como elementos que se somam no tratamento dos saberes da área, dado que uma depende da outra para acontecer. Existe também a possibilidade de a ação problematizada ser discutida na troca argumentativa para além dos individualismos ou contextualismos práticos ou teóricos interpretativos. Mas, para isso, a verdade pronunciada pelas teses deveria ser avaliada como "pretensões de verdade" históricas e provisórias que precisariam ser validadas mediante as referências discursivas e o confronto com o mundo objetivo numa perspectiva de linguagem comum. Validando os saberes no discurso e na ação junto ao mundo, pode-se oferecer mais universalidade à compreensão dos problemas concretos.

Tendo em vista que as práticas e/ou as teorias não possuem o poder de correção de forma independente, a articulação da ação com o discurso tem um papel importante na transformação das pretensões de validade em enunciados desproblematizados a serem reutilizados. Segundo Habermas (2004, p. 49), o discurso é o "[...] único meio disponível para se certificar da verdade, porque não há outra maneira de examinar as pretensões de verdade tornadas problemáticas [...]”, e a ação, o único espaço de prova da adequação ou não do que foi produzido. O que ele busca defender é o discurso como processo epistemológico para o tratamento de verdades tornadas improváveis. A ideia é ultrapassar a relação de submissão entre a teoria e a prática em favor de uma articulação em que ambas se 
complementam, tendo em vista a força da razão comunicativa. Ou seja, para além das compreensões do sujeito em relação ao objeto, trataríamos os saberes práticos no discurso, onde legítimo seria o enunciado aceito por um grupo racionalmente motivado. Segundo Habermas (2004, p. 52), “[...] na medida em que o saber se justifica por um processo de aprendizado que supera os velhos erros mas não nos protege dos novos, cada estado de saber atual permanece relativo à melhor situação epistêmica possível”.

Habermas nos autoriza a pensar assim que o saber problematizado no discurso tem maior chance de êxito na prática, tendo em vista o esgotamento do uso de uma racionalidade comunicativa em que diferentes interpretações acerca do mesmo mundo são colocadas em xeque na troca argumentativa. Diz o autor: "É apenas com a transição da ação para o discurso que os participantes adotam uma atitude reflexiva e, à luz de razões pró e contra apresentadas, disputam pela verdade tematizada de enunciados controversos [...]” (HABERMAS, 2004, p. 49).

Por esse caminho observamos que existem possibilidades nas pesquisas com formação de professores no Brasil de empregar o discurso como intersubjetividade reflexiva capaz de alcançar saberes cada vez mais eficazes na ação, tendo em vista as posições críticas do discurso. Nesse sentido, a prática não seria justificada apenas sob o ponto de vista de um observador, mas por meio de vários observadores que encontrariam no discurso a possibilidade de realizar acordos pela força de uso do melhor argumento. Ao discurso, ou seja, ao trabalho de tese caberia a tarefa de alcançar acordos não só entre os pares especializados, mas entre grupos de interlocutores cada vez amplos, de modo que os acertos pudessem ser apresentados diante de qualquer público, dado que a educação é um fenômeno social, contribuindo para a popularização da ciência e a difusão do conhecimento na sociedade. É um processo de aprendizagem que não acontece apenas na prática, mas circula entre a prática e o discurso, sempre com pretensões de universalidade.

Acreditamos, desse modo, que empregando o discurso enquanto possibilidade de desproblematização reflexiva, as pesquisas com formação de professores poderiam acelerar o progresso dos saberes da área e viabilizar consequências mais positivas nas ações educacionais, tendo em vista que seriam legitimadas pelo esgotamento de uma discussão racional, não por uma interpretação solitária ou apenas de um grupo de pares. Segundo Habermas 
(2004, p. 50), “[...] do ponto de vista de práticas malsucedidas e certezas de ação abaladas, as argumentações têm uma espécie de função reparadora [...]" que ultrapassa o nível interpretativo e descritivo das realidades práticas. Desse modo, a aprendizagem aconteceria não apenas pela articulação entre a experiência na prática e a sua interpretação teórica, mas principalmente pelos acertos discursivos entre as múltiplas interpretações da mesma objetividade.

Nesse aspecto, o contraponto de outras perspectivas é fundamental para que a discussão possa avançar. Por isto esta é apenas uma posição no processo de acertos sobre o assunto; uma posição aberta a críticas e sugestões. O esquema de avaliação que propomos é no sentido discursivo, sendo colocado em questão justamente na análise das teses (resistência do mundo objetivo) para ser recuperado posteriormente com as certezas abaladas ou não. Estamos apresentando as nossas pretensões de validade e propondo argumentos para serem ou não reconhecidos, dado que a sua validade só seria alcançada com o reconhecimento mútuo da proposta.

Em caso afirmativo, poderíamos considerar esta uma abordagem possível de ser validada nas práticas investigativas com formação de professores, na medida em que permite uma aprendizagem comprometida não só com o mundo mas com a racionalidade possível pela comunicação. Preocupa-nos a racionalização cultural, que tende a especializar os estudos com a formação de professores de forma unilateral, coisificando a prática educativa. Por isso, apostamos no entendimento como possibilidade "[...] de coordenação das ações [...]” (HABERMAS, 1987). Poderemos auxiliar, por este caminho, o processo de revisão das investigações na área de formação de professores, que exige de nós um aprendizado comunicativo, o qual não acontecerá imediatamente mas de forma gradativa, conforme a crítica do outro for avaliada como recurso imprescindível para chegarmos a um bom termo com o mundo. 


\section{REFERÊNCIAS}

AMARAL, D. P. Faculdade de Educação da UFRJ: argumentos pela sua constituição como território de formação teórica e prática dos licenciandos. 2008. 258 f. Tese (Doutorado em Educação)-Universidade Federal do Rio de Janeiro, Rio de Janeiro, 2008. Disponível em: <http://www.dominiopublico.gov.br/pesquisa/ResultadoPesquisaPeriodicoForm. do >. Acesso em: 19 abr. 2011.

ASSIS, G. S. Ideário freireano: um referencial teórico-metodológico para a formação políticopedagógica do professor. 2007. 175 f. Tese (Doutorado em Educação)-Universidade Federal da Paraíba, João Pessoa, 2007. Disponível em: < http:/ /www.dominiopublico.gov. br/pesquisa/ResultadoPesquisaPeriodicoForm.do>. Acesso em: 19 abr. 2011.

BITTENCOURT, R. L. Formação de professores em nivel de graduação na modalidade EAD: o caso da pedagogia da UDESC - Pólo de Criciúma - SC. 2008. 254 f. Tese (Doutorado em Educação)-Universidade Federal do Rrio Grande do Sul, Porto Alegre, 2008. Disponível em: <http://www.dominiopublico.gov.br/pesquisa/PesquisaPeriodicoForm.jsp>. Acesso em: 21 abr. 2011.

BORTOLINI, M. R. A pesquisa na formação de professores: experiências e representações. 2009.196 f. Tese (Doutorado em Educação)-Universidade Federal do Rio de Janeiro, Rio de Janeiro, 2009. Disponível em: < http://www.dominiopublico.gov.br/pesquisa/PesquisaPeriodicoForm. jsp>. Acesso em: 19 abr. 2011.

BRANCO, R. F. G. R. Capacitação de professores de classe hospitalar em relação professor-aluno/ paciente na perspectiva balintiana. 2008. 180 f. Tese (Doutorado em Educação)-Universidade Federal de Goiás, Goiânia, 2008. Disponível em: < http://www.dominiopublico.gov.br/ pesquisa/PesquisaPeriodicoForm.jsp>. Acesso em: 19 abr. 2011.

CABRAL, A. B. O texto, o contexto e o pretexto ensino de literatura, após a reforma do ensino médio. 2008. 247 f. Tese (Doutorado em Educação)-Universidade Federal de São Carlos, São Carlos, 2008. Disponível em: <http://www.dominiopublico.gov.br/pesquisa/ PesquisaPeriodicoForm.jsp>. Acesso em: 19 abr. 2011.

CASTANÕN, G. A. Construcionismo social: uma crítica epistemológica. Temas em Psicologia da SBP, Rio de Janeiro, v. 12, n. 1, p. 67-81. 2004.

CESÁRIO, M. Formação de professores de educação física da Universidade Estadual de Londrina: tradução do projeto curricular pelos professores. 2008. 221 f. Tese (Doutorado em Educação)-Universidade Federal de São Carlos, São Carlos, 2008. Disponível em: < http:// www.dominiopublico.gov.br/pesquisa/PesquisaPeriodicoForm.jsp>. Acesso em: 19 abr. 2011. DAL-FORNO, J. P. Formação de formadores e educação inclusiva: análise de uma experiência via internet. 2009. 319 f. Tese (Doutorado em Educação)-Universidade Federal de São Carlos, São Carlos, 2009. Disponível em: <http://www.dominiopublico.gov.br/pesquisa/ PesquisaPeriodicoForm.do>. Acesso em: 19 abr. 2011.

DIAS, M. B. L. O jogo estésico: uma possibilidade de educação integral. 2007. 119 f. Tese (Doutorado em Educação)-Universidade Federal do Rio Grande do Sul, Porto Alegre, 2007. Disponível em: < http://www.dominiopublico.gov.br/pesquisa/PesquisaPeriodicoForm. jsp>. Acesso em: 19 abr. 2012.

ECO, H. Como se faz. uma tese. São Paulo: Perspectiva, 2006. 
ESTEBAN, M. P. S. Pesquisa qualitativa em educação: fundamentos e tradições. Porto Alegre: Artmed, 2010.

HABERMAS, J. Verdade e justificação: ensaios filosóficos. São Paulo: Loyola, 2004.

FISCHER, R. M. B. Foucault e a análise do discurso em educação. Cadernos de pesquisa, São Paulo, n. 114, nov. 2001.

LAWN, C. Compreender Gadamer. Petrópolis, Rio de Janeiro: Vozes, 2007.

MACEDO, R. S. Compreender/mediar a formação: o fundante da educação. Brasília: Líber Livro Editora, 2010.

MELO, M. J. M. D. Olhares sobre a formação dos professor de matemática: imagem da profissão e escrita de si. 2008. 322 f. Tese (Doutorado em Educação)-Universidade Federal do Rio Grande do Norte, Natal. 2008. Disponível em: <http://www.dominiopublico.gov.br/ pesquisa/PesquisaPeriodicoForm.jsp>. Acesso em: 19 abr. 2011.

MELO, G. F. Tornar-se professor: a formação desenvolvida nos cursos de Física, Matemática e Química da Universidade Federal de Uberlândia Goiânia. 2007. 220 f. Tese (Doutorado em Educação)-Universidade Federal de Goiás, Goiânia, 2007. Disponível em: <http://www. dominiopublico.gov.br/pesquisa/PesquisaPeriodicoForm.jsp>. Acesso em: 19 abr. 2011. MINASI, L. F. Formação de professores em serviço: Contradições na prática pedagógica. 2008. 208 f. Tese (Doutorado em Educação)-Universidade Federal do Rio Grande do Sul. Porto Alegre, 2008. Disponível em: <http://www.dominiopublico.gov.br/pesquisa/ ResultadoPesquisaPeriodicoForm.do>. Acesso em: 19 abr. 2011.

MORIN, E. Ciência com consciência. 11. ed. Rio de Janeiro: Bertrand Brasil, 2008.

MORIN, E. O método 5: a humanidade da humanidade. Porto Alegre: Sulina, 2007.

MOSCOVICI, S. Representações Sociais: investigações em psicologia social. 8. ed. Petrópolis: Vozes, 2011.

OLIVEIRA, G. M. S. Concepções de orientadores acadêmicos e estudantes dos cursos de pedagogia a distância da Universidade Federal de Mato Grosso sobre ensino e aprendizagem. 2008. 137 f. Tese (Doutorado em Educação)-Universidade Federal de Santa Catarina, Florianópolis, 2008. Disponível em: <http://www.dominiopublico.gov.br/pesquisa/PesquisaPeriodicoForm. jsp>. Acesso em: 19 abr. 2012.

PALOMINO, T. J. A aprendizagem da docência de uma professora iniciante: um olhar com foco na intermulticulturalidade. 2009. 254 f. Tese (Doutorado em Educação)-Universidade Federal de São Carlos, São Carlos, 2009. Disponível em: <http://www.dominiopublico. gov.br/pesquisa/PesquisaPeriodicoForm.jsp>. Acesso em: 19 abr. 2011.

PEREZ, M. Grandezas e medidas: representações sociais de professores do ensino fundamental. 2008. 201 f. Tese (Doutorado em Educação)-Universidade Federal do Paraná, Curitiba, 2008. Disponível em: <http://www.dominiopublico.gov.br/pesquisa/ PesquisaPeriodicoForm.jsp>. Acesso em: 19 abr. 2011.

PIRES, R. C. M. A formação inicial do professor pesquisador universitário no Programa Institucional de Bolsas de Iniciação Cientifica - PIBIC/CNPq e a prática profissional de seus egressos: um estudo de caso na Universidade do Estado da Bahia. 2008. 356 f. Tese (Doutorado em Educação)Universidade Federal do Rio Grande do Sul, Porto Alegre, 2008. Disponível em: < http:/ / www.dominiopublico.gov.br/pesquisa/PesquisaPeriodicoForm.jsp>. Acesso em: 19 abr. 2011. SANTOS, S. Processos formativos e reflexivos: contribuições para o desenvolvimento profissional de professores. 2008. 264 f. Tese (Doutorado em Educação)-Universidade Federal de São 
Carlos, São Carlos, 2008. Disponível em: <http://www.dominiopublico.gov.br/pesquisa/ PesquisaPeriodicoForm.jsp>. Acesso em: 19 abr. 2011.

SILVA, L. C. Políticas públicas e formação de professores: vozes e vieses da educação inclusiva. 2009. 344 f. Tese (Doutorado em Educação)-Universidade Federal de Uberlândia, Uberlândia, 2009. Disponível em: <http://www.dominiopublico.gov.br/pesquisa/ PesquisaPeriodicoForm.jsp>. Acesso em: 21 abr. 2011.

SILVA, M. B. O processo de construcão de identidades individuais e coletivas do "ser tutor" no contexto da educação a distância, hoje. 2008. 217 f. Tese (Doutorado em Educação)-Universidade Federal do Rio Grande do Sul, Porto Alegre, 2008a. Disponível em: <http://www.dominiopublico. gov.br/pesquisa/PesquisaPeriodicoForm.jsp>. Acesso em: 19 abr. 2011.

SILVA, J. A. M. A investigação-ação educacional e as ações de linguagem como princípios formativos do ser professor. 2008. 295 f. Tese (Doutorado em Educação)-Universidade Federal da Bahia, Salvador, 2008b. Disponível em: <http://www.dominiopublico.gov.br/pesquisa/ ResultadoPesquisaPeriodicoForm.do>. Acesso em: 21 abr. 2011.

TARDIF, M. Saberes docentes \& formação profissional. 11. ed. Petrópolis: Vozes, 2010.

TEIXEIRA, V. L. A formação continuada de professores na rede municipal de educação de Niterói: desafios para a construção de uma política pública. 2009. 249 f. Tese (Doutorado em Educação)-Universidade Federal Fluminense, Niterói, 2009. Disponível em: <http:// www.dominiopublico.gov.br/pesquisa/ResultadoPesquisaPeriodicoForm.do $>$. Acesso em: 19 abr. 2011.

WOLFF, E. A. Fundamentos psicossociais da formação de educadores do campo. 2007. 225 f. Tese (Doutorado em Educação)-Universidade Federal do Rio Grande do Sul, Porto Alegre, 2007. Disponível em: <http://www.dominiopublico.gov.br/pesquisa/ ResultadoPesquisaPeriodicoForm.do>. Acesso em: 19 abr. 2011.

ZANETTI, S. G. "Comunidades de professores" sob a ótica de pesquisadores: análise de três casos típicos. 2008. 202 f. Tese (Doutorado em Educação)-Universidade Federal de São Carlos, São Carlos, 2008. Disponível em: < http://www.dominiopublico.gov.br/pesquisa/ ResultadoPesquisaPeriodicoForm.do>. Acesso em: 19 abr. 2011. 


\section{NOTAS}

${ }^{1}$ Segundo Habermas, “[...] ao realismo da práxis cotidiana corresponde um conceito subjacente, porém apenas de modo performativo - de verdade absoluta, de verdade sem índex epistêmico [...]" (2004, p. 49).

${ }^{2}$ Em Verdade e justificação, Habermas (2004) associa a teoria epistemológica do campo discursivo (relação sujeito-sujeito) a um conceito não epistemológico concebido em termos pragmatistas (verdades não questionadas).

Recebido: 20/07/2012

Aprovado: 30/11/2012

Contato:

Universidade Federal de Santa Maria Rua Heitor da Graça Fernandes, 280/401. Bairro Camobi CEP 97105-170

Santa Maria, RS Brasil 